\title{
Shear Strains at Service Load Conditions in Cracked Reinforced Concrete Elements Subjected to Shear
}

\author{
Khaldoun N. Rahal \\ Civil Engineering Department, Kuwait University, P.O. Box 5969, Safat 13060, Kuwait \\ Corresponding Author: Khaldoun.rahal@ku.edu.kw
}

Submitted: $22 / 10 / 2019$

Revised: $\quad 07 / 08 / 2020$

Accepted: 16/08/2020

\begin{abstract}
The contribution of the shear strains to the overall deformations of reinforced concrete (RC) elements is typically neglected. However, when RC cracks in shear, its shear modulus is significantly reduced, and the contribution of the shear strains to the overall deformations of the elements is increased. Experimental testing has shown that shear deformations can be significant. Under service conditions, RC can be cracked in shear and hence, a simple method for the calculation of the effective cracked shear modulus is desired. Research has shown that the part of the shear response after cracking and before yielding can be well modeled using a straight line. This paper uses existing experimental data and the equations of the modified compression field theory (MCFT) to examine this part of the response in $\mathrm{RC}$ membrane elements and to develop two simple equations that can be used to characterize the straight line. The proposed equations are evaluated by comparing their results with existing experimental data on the shear response of thin RC membrane elements. The comparison includes the post-cracking response and the shear strains at estimated service level loading. A very good agreement is obtained between the experimental and the calculated results. The simplicity of the proposed equations is illustrated using a numerical example.
\end{abstract}

Keywords: Concrete; Cracking; Modulus; Reinforcement; Shear; Strain.

\section{INTRODUCTION}

The deformations in structural RC elements at service load conditions are typically required not to exceed prescribed limits. Deformations in RC elements such as beams for example have long been considered to be predominantly due to flexure. While the flexural strength is calculated with reasonable accuracy, the instantaneous and long-term flexural deformations are not (Nilson et al., 2010). With the difficulty in obtaining an accurate calculation of the flexural contribution to the overall deformations, it was practical to neglect the relatively less influential contribution of the shear forces.

However, experiments have shown that the contribution of shear strains to the overall deflections can be considerable not only in shear-critical but also in flexure-critical elements (Huang et al., 2019a; Beyer et al., 2011; Debernardi et al., 2006; Hansapinyo et al., 2003; Vecchio and Emara, 1992). The cracking of concrete in elements subjected to service level shear stresses causes a significant degradation in the shear modulus. This leads to deformations, which are considerably larger than those calculated based on the assumption that concrete behaves in linear-elastic manner (Huang et al., 2019b; Rahal, 2010). In addition, advances in the modeling of the behavior of RC allowed for a more accurate calculation of the flexural contribution to the deformations. Thus, an accurate calculation of the shear contribution to the deformations at service conditions is valuable. This can be achieved by the calculation of the shear strains and the effective shear modulus at service load conditions, with due consideration of the effects of concrete cracking on the degradation of the shear modulus. 
Advanced behavioral models are available to calculate the shear strains in RC elements and to capture the effects of concrete cracking, concrete tension stiffening, and steel yielding on the deformations. The MCFT (Vecchio and Collins, 1986; Bentz, 2000) and the fixed angle softened truss model (FASTM) (Pang and Hsu, 1996) are two wellknown examples. These models use the conditions of equilibrium of stresses, compatibility of strains, and realistic constitutive model of cracked concrete to calculate the stresses and strains in the concrete and steel. Tension stiffening and compression softening are two of the main features, which allow the methods to provide accurate modeling of the shear behavior. To account for these and for numerous other factors, the equations of these advanced models are complex. Calculating the response requires iterations and is practical only with the use of computers, which limits their use. A simpler method is valuable for more common uses.

Research has shown that a significant part of the post-cracking response of $\mathrm{RC}$ elements can be modeled using a straight line (Rahal, 2010). This part of the post-cracking behavior extends up to the occurrence of steel yielding or concrete crushing, whichever takes place first. RC elements subjected to service level stresses typically fall within this part of the response. It is of interest to find a simple equation for this line. This will enable an accurate calculation of the shear strains at service conditions.

This paper evaluates the existing shear tests of RC membrane elements and the equations and results of the MCFT to characterize the post-cracking behavior. Two simple noniterative empirical equations that can be used to model the linear part of the post-cracking shear stress-strain response are proposed. These equations can be used to calculate the shear strain and consequently to calculate an effective cracked shear modulus at service $G_{\text {serv }}$.

\section{POST-CRACKING SHEAR BEHAVIOR OF RC ELEMENTS}

Figure 1 shows a thin element subjected to in-plane shear stresses $(v)$. This element is reinforced with orthogonal steel in the x- and y-directions. The ratios of reinforcement in these two directions are $\rho_{x}$ and $\rho_{y}$ and the yield strengths are $f_{y-x}$ and $f_{y-y}$ respectively. The concrete compressive strength is $f_{c}^{\prime}$.

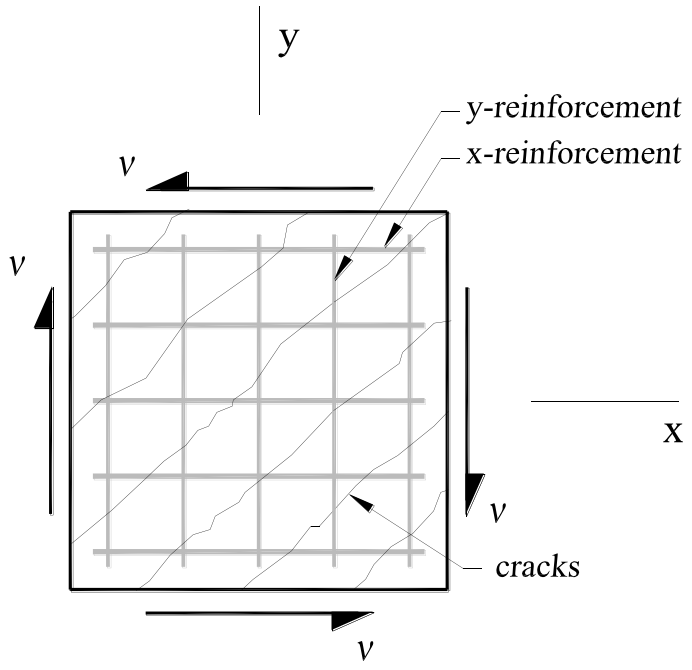

Figure 1. Orthogonally reinforced concrete membrane element subjected to in-plane shear stresses.

Figure 2 shows a shear stress-strain relationship curve for an under-reinforced (UR) normal strength concrete (NSC) element tested by Pang and Hsu (1995). Before reaching the cracking stress $\left(v_{c r}\right)$, the behavior is linear and relatively stiff. The uncracked shear modulus in this region is named $G_{\text {uncr }}$. When the concrete cracks, its ability to resist the applied stresses decreases. The mechanism of resistance changes to allow the steel to be more actively engaged in the resistance. To accommodate this change, the deformations are increased without a significant change in the resisted stress. A nearly horizontal transition zone is observed in the response curve, indicating the shift in the response from that of an uncracked to that of a cracked composite material. 


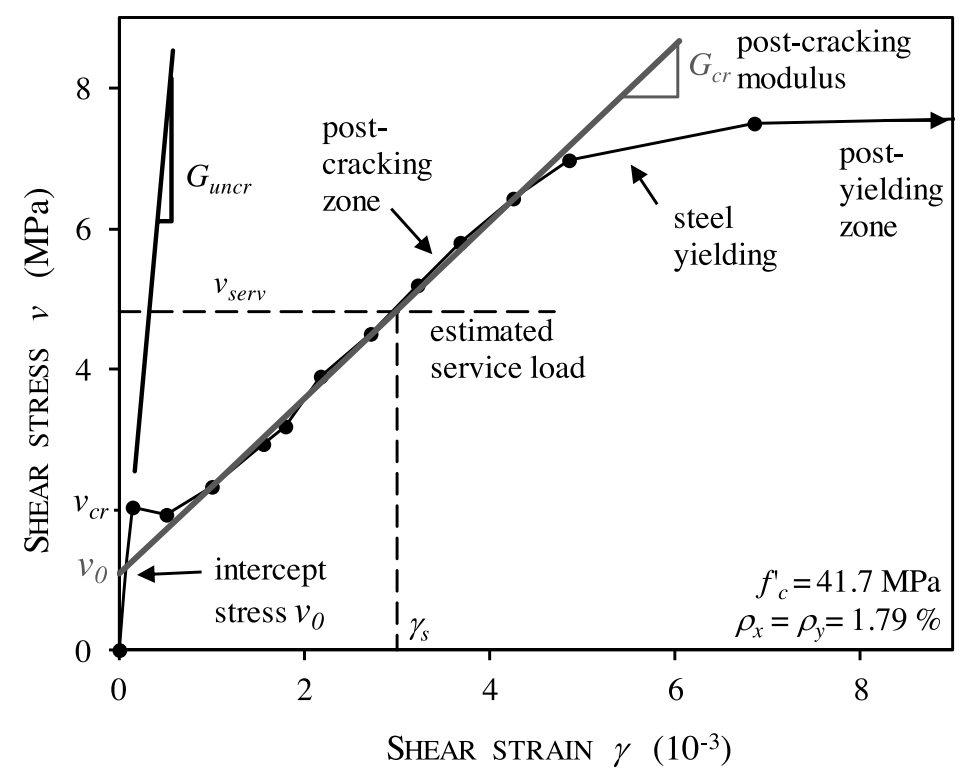

Figure 2. Shear response of membrane specimen A3 tested by Pang and Hsu (1995).

The behavior after cracking is significantly softer than that before cracking. The tangent shear modulus after cracking $\left(G_{c r}\right)$ is a fraction of that before cracking $\left(G_{u n c r}\right)$ (Rahal, 2010). Another severe degradation in the modulus takes place when the steel reinforcement yields. The element shown in Figure 2 was reinforced with similar orthogonal reinforcement $\left(\rho_{x}=\rho_{y}=1.79 \%\right)$. The response between the ends of the transition zone and before yielding of the reinforcement is nearly linear. At higher stresses, the reinforcement in the two directions yields, and the response curve becomes nearly horizontal. The post-yield part of the response is not shown for clarity. In UR elements with unequal orthogonal reinforcement $\left(\rho_{x} \neq \rho_{y}\right)$, the transition between the post-cracking zone and the post-yielding zone shows a more gradual softening in the response curve.

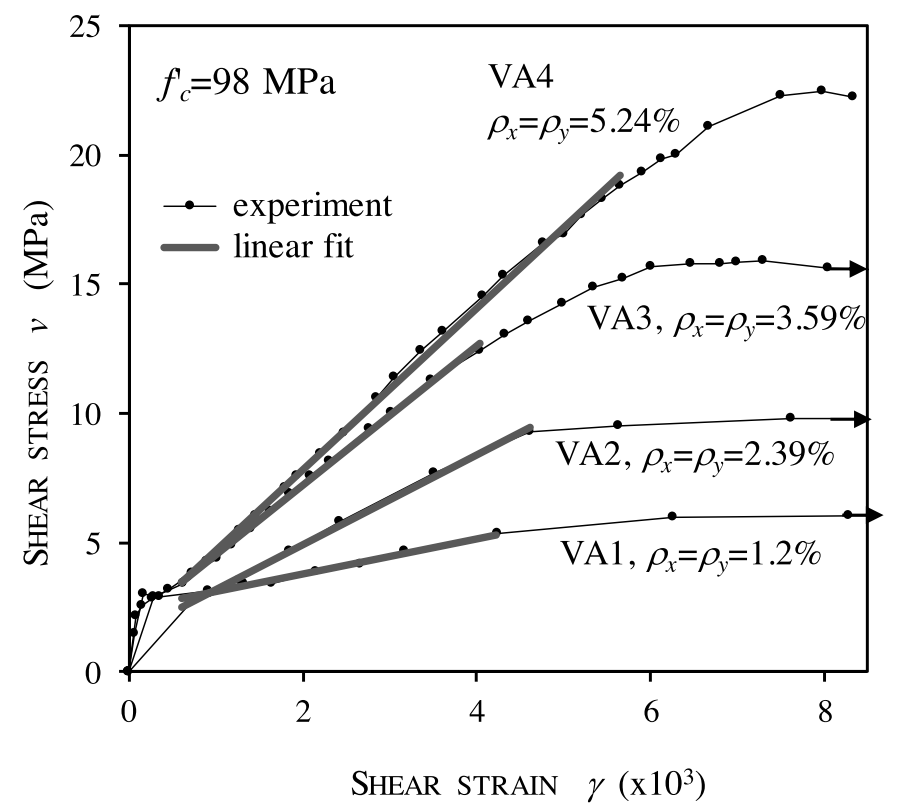

Figure 3. Response of specimens VA1 to VA4 tested by Hsu and Zhang (1998). 
Figure 3 shows the response curves of four membrane specimens tested in pure shear by Hsu and Zhang (1998). The reinforcement ratios $\left(\rho_{x}=\rho_{y}\right)$ ranged from $1.2 \%$ to $5.24 \%$. Specimens VA1 to VA3 failed in an under-reinforced mode, while VA4 failed in an over-reinforced (OR) mode. The increase in the reinforcement ratios increased the strength and reduced the ductility. However, in all four specimens, the major part of the post-cracking behavior can be represented by a straight line.

The stress at service conditions $v_{\text {serv }}$ can be estimated to be $70 \%$ of the ultimate shear strength $v_{u}$ (Al-Shaleh and Rahal 2007). The stress $v_{s e r v}$ is typically larger than the cracking shear stress $\left(v_{c r}\right)$ and smaller than the shear stresses, which cause a major degradation in the shear modulus (steel yielding, or concrete severe softening or concrete crushing). Hence, the service stress typically falls within the nearly linear part of the response curve shown in Figures 2 and 3, irrespective of the mode of failure (MOF) of the element. Figure 2 shows that the shear strains at service are severely underestimated if they are calculated based on the uncracked shear modulus $G_{\text {uncr }}$. For specimen A3 for example, the measured shear strain at $v_{\text {ser }}$ is $3.37 \times 10^{-3}$ while the calculated strain based on linear-elastic uncracked behavior is about $0.47 \times 10^{-3}$.

The post-cracking response extending from the end of the transition zone to the onset of softening caused by steel yielding or concrete softening/crushing can be idealized as a straight line. The line is characterized using two values: the slope $G_{c r}$ and the intercept stress $v_{0}$ with the vertical axis. These two characteristics of the post-cracking response are shown in Figure 2 for specimen A3. When these two values are available, it would be possible to easily calculate the shear strains at service $\left(\gamma_{s}\right)$ and the corresponding effective shear modulus $G_{\text {serv }}$.

Data from tests on RC elements are available in the literature. Results such as those shown in Figure 3 show that an increase in the reinforcement ratios increases the slope $G_{c r}$ but has limited effect on the intercept point $v_{0}$. However, the number of the tests, especially the fully documented ones, is limited. In addition, the intercept stress $v_{0}$ is sensitive to the selection of the best-fit straight line, leading to a significant scatter in the results and a difficulty in identifying experimental trends. Consequently, the available experimental data is not sufficient to develop accurate empirical equations for $v_{0}$ and $G_{c r}$. It is proposed to use the results of an advanced behavioral model to develop empirical equations. Then, the evaluation of their accuracy can then be based on a comparison with the existing experimental data.

The next sections use the equations and the calculations of the MCFT to evaluate the effects of the main parameters that influence $v_{0}$ and $G_{c r}$ and to develop two simple empirical equations to calculate them. Then, the results of the proposed equations leading to $\gamma_{s}$ are compared with the experimental results from panels tested in pure shear at the University of Houston under strain control. These experimental results are well-documented and were not used in the development of the MCFT. Hence, they provide an unbiased evaluation of the equations.

\section{ANALYSIS USING MCFT}

Figure 4 summarizes the equations of the MCFT for RC elements subjected to pure shear stresses (Bentz 2000). It lists the equilibrium equations, compatibility conditions, and the constitutive models for concrete and steel. The shear response depends on the strength and the behavior of the concrete in compression and in tension, the ratio and the yield strength of the orthogonal reinforcement, the nominal maximum aggregate size $\left(a_{g}\right)$, and the crack spacing parameters $S_{x}$ and $S_{y}$.

This paper is concerned with the linear behavior extending from the end of the transition zone till the start of yielding (or concrete softening/crushing, whichever occurs first). In this part of the behavior, the steel is linear-elastic irrespective of the MOF of the element and hence, the response is not affected by the yielding strength since, in this region, the steel "does not know" how far it is from yielding. Hence, the yielding strength of the x- and y-reinforcement do not affect the equations of $v_{0}$ and $G_{c r}$. On the other hand, the check on the ability of the crack to transfer the shearing stresses (Eq. 18 in Figure 4) affects the analysis only after yielding of the reinforcement and hence is not relevant to part of the behavior under investigation. Consequently, the aggregate size $\left(a_{g}\right)$ and the crack spacing parameters $S_{x}$ and $S_{y}$ are not included in the proposed equations. 


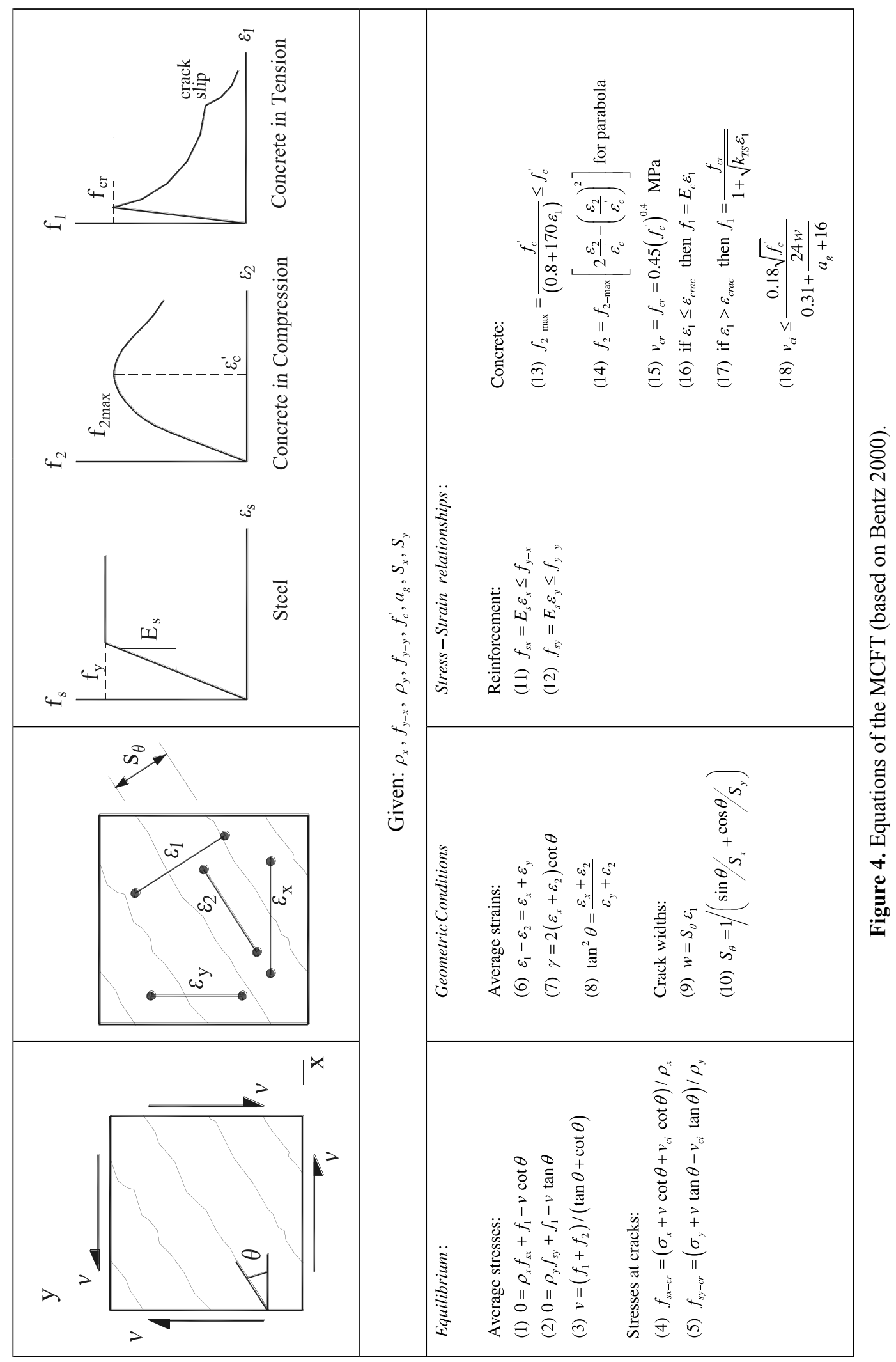


The post-cracking behavior is affected by the constitutive model for concrete in compression (before the peak stress) and by the part of the concrete tension model after cracking and before crack slip (slip takes place after yielding). The latter is affected by the concrete strength in tension $f_{c r}$ [taken as $0.45\left(f_{c}^{\prime}\right)^{0.4}$ as shown in Eq. (15)] and in the tension stiffening factor $\left(k_{T S}\right)$ shown in Eq. (17).

Eq. (14) in Figure 4 shows the equation for a parabolic stress-strain relationship of softened concrete in compression. This model is suitable for normal strength concrete. To account for the stiffer pre-peak behavior and the larger strain $\left(\varepsilon_{c}\right)$ at peak stress in high strength concrete (HSC), the MCFT recommends the use of the equations based on the modified Popovics model. Details of this model can be found elsewhere (Collins et al. 1993).

For the concrete tension stiffening, Collins et al. (1996) recommends using a factor $k_{T S}$ of 500 instead of the value of 200 suggested by the original formulations of the MCFT (Vecchio and Collins 1986). The value of 500 was considered to be more suitable for a wider range of elements including the thicker University of Toronto shell elements such as those tested by Khalifa (1986). Since this paper aims at proving that simple empirical equations can be obtained, the development of the equations will be based on $k_{T S}=500$ and the modified Popovics model for concrete in compression. The compression softening shown in Eq. (13) in Figure 4 is the equation proposed in the original formulation of the MCFT (Vecchio and Collins 1986).

The ratios of reinforcement and the concrete compressive strength are the main factors that are considered in the development of the equations for $v_{0}$ and $G_{c r}$. The equations of the MCFT are coded in a spreadsheet to generate the full shear stress-strain response of membrane elements. This spreadsheet is used to analyze elements to generate data that can be used to develop the empirical equations for $v_{0}$ and $G_{c r}$.

\section{Analysis sets}

A total of sixty-seven elements in nine sets were selected for analysis using the MCFT. See Table 1. The properties of these elements covered a wide range of possible properties. The concrete strengths ranged from 20 to $110 \mathrm{MPa}$. For each concrete compressive strength, reinforcement ratios were selected to cover under-reinforced, partially underreinforced (PUR), and over-reinforced modes of failure. To decide on the balanced reinforcement corresponding to a specific concrete strength, the equation proposed by Rahal (2008) was used. The balanced amount of reinforcement in each direction corresponds to mechanical reinforcement indexes $\omega=\rho f_{y} / f_{c}^{\prime}$ ranging linearly from about 0.31 for a $20 \mathrm{MPa}$ concrete to about 0.21 for a $110 \mathrm{MPa}$ concrete.

As shown in Table 1, the analysis set 1 was conducted on elements reinforced with $\omega_{x}=\omega_{y}=0.1$. The concrete strengths ranged from 20 to $110 \mathrm{MPa}$, and consequently the reinforcement ratios $\rho_{x} \rho_{y}$ varied. The relatively low $\omega$ ensured that all elements were UR. The analysis set 2 was similar to set 1 except that the reinforcement indexes were larger $\left(\omega_{x}=\omega_{y}=0.2\right)$. They remained smaller than the balanced reinforcement and hence, the elements in this set were also UR. In the analysis set 3 , the reinforcement indexes $\left(\omega_{x}=\omega_{y}=0.35\right)$ were increased above the balanced reinforcement level, and the elements were OR. 
Table 1. Summary of MCFT analyses.

\begin{tabular}{|c|c|c|c|c|c|}
\hline $\begin{array}{c}\text { Analysis } \\
\text { set }\end{array}$ & $\begin{array}{c}f_{c}^{\prime} \\
\text { (MPa) }\end{array}$ & $\omega_{x}$ & $\omega_{y}$ & $\begin{array}{c}\rho_{x} \\
\text { (percent) }\end{array}$ & $\begin{array}{c}\rho_{y} \\
\text { (percent) }\end{array}$ \\
\hline 1 & 20 to 110 & 0.10 & $=\omega_{x}$ & 0.5 to 2.75 & $=\rho_{x}$ \\
\hline 2 & 20 to 110 & 0.20 & $=\omega_{x}$ & 1.0 to 5.5 & $=\rho_{x}$ \\
\hline 3 & 20 to 110 & 0.35 & $=\omega_{x}$ & 1.75 to 9.63 & $=\rho_{x}$ \\
\hline 4 & 20 & 0.08 to 0.33 & $=\omega_{x}$ & 0.4 to 1.65 & $=\rho_{x}$ \\
\hline 5 & 50 & 0.05 to 0.60 & $=\omega_{x}$ & 0.63 to 7.5 & $=\rho_{x}$ \\
\hline 6 & 100 & 0.03 to 0.30 & $=\omega_{x}$ & 0.75 to 7.5 & $=\rho_{x}$ \\
\hline 7 & 20 & 0.40 & 0.04 to 0.6 & 2.0 & 0.2 to 3.0 \\
\hline 8 & 50 & 0.32 & 0.02 to 0.32 & 4.0 & 0.25 to 4.0 \\
\hline 9 & 100 & 0.28 & 0.01 to 0.32 & 7.0 & 0.25 to 8.0 \\
\hline
\end{tabular}

The concrete compressive strengths in analysis sets 4, 5, and 6 were 20, 50, and $100 \mathrm{MPa}$ respectively. In each set, elements of different amounts of equal reinforcement $\left(\omega_{x}=\omega_{y}\right)$ were analyzed. Elements with reinforcement indexes smaller than balanced levels were UR, while the remaining were OR.

In the analysis set $7, f_{c}^{\prime}$ was selected to be $20 \mathrm{MPa}$. The x-direction index $\omega_{x}$ was set equal to 0.4 , while the $\mathrm{y}$-direction reinforcement index $\omega_{y}$ varied. The relatively large value of $\omega_{x}$ corresponded to over-reinforcement in the x-direction. The y-reinforcement was under-reinforced for $\omega_{y}$ values less than about 0.31 and over-reinforced for larger values. Analysis sets 8 and 9 were similar to set 7 except that $f_{c}^{\prime}$ was 50 and $100 \mathrm{MPa}$, respectively.

The shear response of the sixty-seven elements was obtained using the MCFT analyses. For each response curve, the linear part of the post-cracking and pre-peak region was identified, and a simple regression analysis was performed to obtain the best-fit straight line. The equation of the line provided the required information on $v_{0}$ and $G_{c r}$.

\section{INTERCEPT POINT $v_{0}$}

Figure 5(a) plots the values of $v_{0}$ calculated using the MCFT versus $f_{c}^{\prime}$ for the analysis sets 1 to 3 . The results from all three sets show that the $v_{0}$ was proportional to $\left(f_{c}^{\prime}\right)^{0.4}$ irrespective of the reinforcement ratios. As the compressive strength $f_{c}^{\prime}$ increased, the cracking strength $f_{c r}$ increased. The response curve was pushed upwards leading to a larger value of $v_{0}$. The amount of reinforcement in the three different sets varied considerably, but the effect of this variation on $v_{0}$ was limited. This indicates that $v_{0}$ was not significantly influenced by the amount of reinforcement nor the MOF. It is to be noted that the $\mathrm{x}$-direction steel and the $\mathrm{y}$-direction steel in any specific specimen of the sets 1, 2, and 3 were similar.

Figure 5(b) plots the MCFT calculated values of $v_{0}$ versus the equal reinforcement ratios $\left(\rho_{x}=\rho_{y}\right)$ for the analysis sets 4 to 6 . In each of the sets, the intercept point was nearly constant. This indicates again that $v_{0}$ is not significantly influenced by the amount of reinforcement for these sets of analyses. The results of analysis sets 4 to 6 are also plotted in Figure 5(a) and fit within the general trend previously observed. It is to be noted again that the $\mathrm{x}$-direction steel and the y-direction steel in any specimen of these sets were similar.

Based on the above, a best-fit curve for the $v_{0}$ can be obtained using $v_{0}=0.3\left(f_{c}^{\prime}\right)^{0.4}$. A change in the equation for $f_{c r}$ (given in Eq. 15) in the analysis led to a proportional change in the intercept stress. Hence, it is more appropriate to relate $v_{0}$ to $f_{c r}$ as follows: 
$v_{0}=0.3\left(f_{c}^{\prime}\right)^{0.4}=\frac{2}{3} f_{c r}$

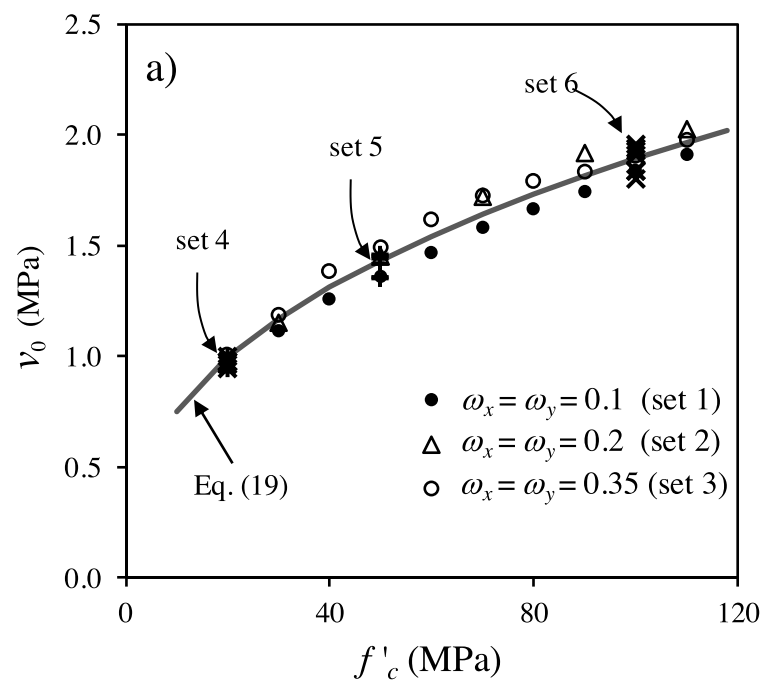

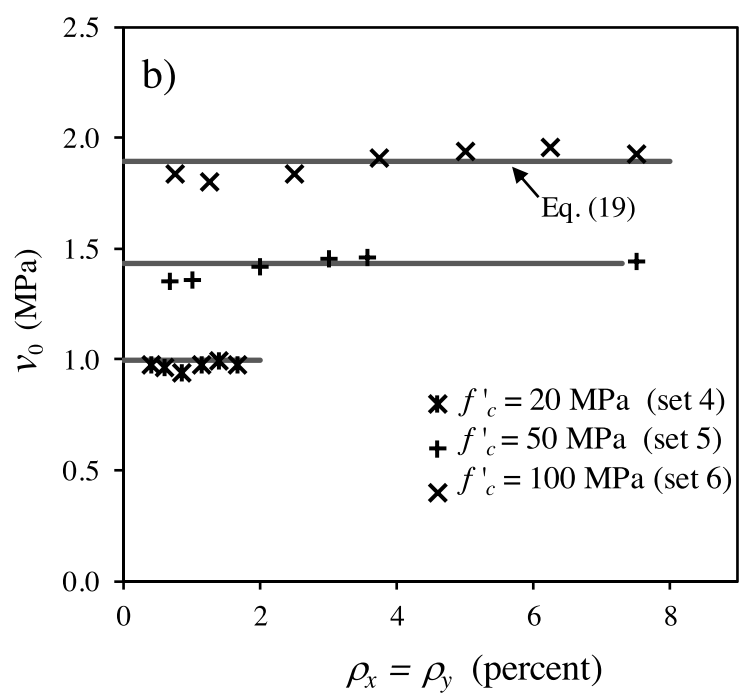

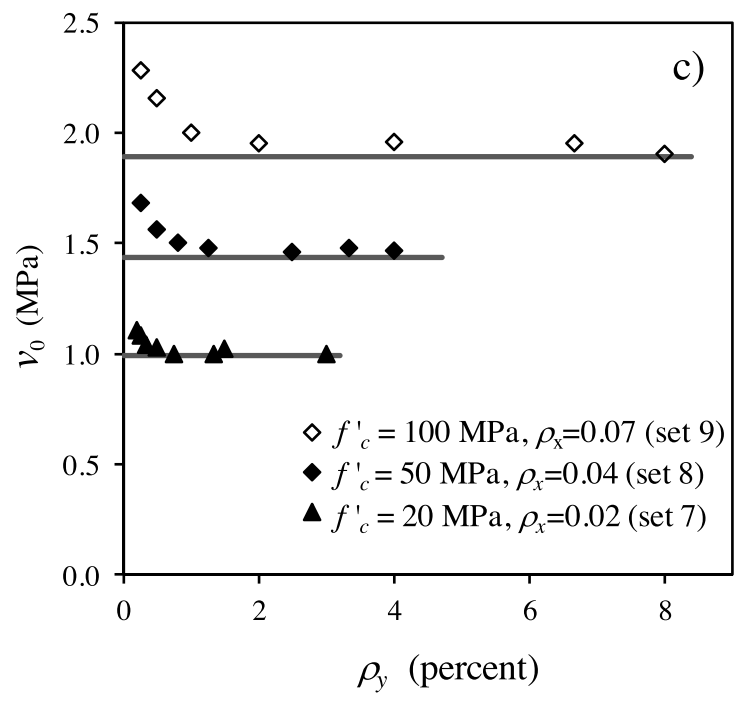

Figure 5. Development of equation for $v_{0}$.

The calculations of Eq. (19) are plotted in Figures 5(a) and 5(b), and a very good agreement with the results of the MCFT is obtained.

Figure 5(c) plots the calculated values of $v_{0}$ versus the reinforcement ratio $\rho_{y}$ which was a variable in the sets 7 to 9 . The values of $\rho_{x}$ were relatively large to ensure over-reinforcement in the x-direction. It is shown that, for considerably different orthogonal reinforcement ratios, Eq. (19) underestimates the intercept stress. If the reinforcement in one direction is significantly weaker than that in the other one, the modulus after cracking becomes slightly softer. Consequently, the intercept point is higher. A survey of existing tests on membrane elements revealed that, in the most extreme case, the ratio of the larger to the smaller reinforcement ratios in a single element was 9. For such case, Eq. (19) underestimates the MCFT result by less than $9 \%$ for the three grades of concrete used. This is a limited difference 
that can be neglected. However, if the effect of unequal reinforcement is to be accounted for, Eq. (19) can be changed to include a modification factor as follows:

$$
v_{0}=\frac{2}{3} f_{c r}\left(0.99+0.01 \frac{\rho_{\max }}{\rho_{\min }}\right)
$$

where $\rho_{\max }$ and $\rho_{\min }$ are the larger and the smaller values of $\rho_{x}$ and $\rho_{y}$ respectively. The modification factor becomes unity if the two reinforcement ratios are equal and increases as the ratio of $\rho_{\max }$ to $\rho_{\min }$ increases.

Table 2. Summary on ratios of MCFT to proposed equations results for 67 analysis data points.

\begin{tabular}{|c|c|c|c|}
\hline & Eq. (19) & Eq. (20) & Eq. (21) \\
\hline Mean & 1.02 & 1.0 & 1.02 \\
\hline Coefficient of variation & $5.0 \%$ & $3.0 \%$ & $8.0 \%$ \\
\hline
\end{tabular}

Table 2 reports a summary of a comparison between the MCFT data and the results of Eqs. (19) and (20). The ratios of the MCFT values of $v_{0}$ to those calculated using Eq. (19) were computed for the sixty-seven data points. The average value of the ratios was 1.02, and the coefficient of variation was 5\%. For Eq. (20), these values were 1.0 and $3 \%$, respectively. Table 2 shows that the results improved when Eq. (20) was used instead of Eq. (19). However, it is not likely that the use of Eq. (20) would be necessary in most practical cases because the impact on the calculation of the shear strain $\gamma_{s}$ is minimal as is shown later in the numerical example. Figure 6 plots a comparison between the results of Eq. (19) and those from the MCFT. A good agreement is observed.

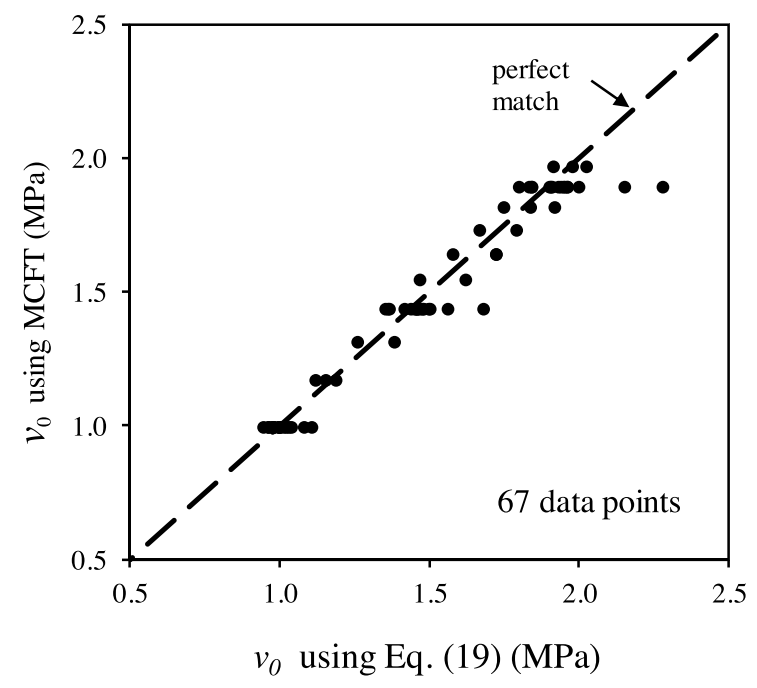

Figure 6. Comparison between $v_{0}$ results from MCFT and from Eq. (19).

\section{Slope $G_{c r}$}

Figure 7(a) plots the MCFT values of $G_{c r}$ versus $\rho_{x}\left(=\rho_{y}\right)$ for the results of the normal-strength concrete set 4, the medium-strength concrete (MSC) set 5, and the high-strength concrete set 6 . As the amount of reinforcement increases, the slope of the post-cracking line increases but at a decreasing rate. For all three concrete strengths, the same trend is observed, and a single equation can be used to fit the data. Figure 7(b) plots $G_{c r}$ versus $f_{c}^{\prime}$ for the results of sets 1 to 3. In each set, the mechanical reinforcement indexes $\omega=\rho f_{y} / f_{c}^{\prime}$ remained constant. As $f_{c}^{\prime}$ increased, the reinforcement ratio $\rho$ increased proportionally, leading to higher values of $G_{c r}$. 

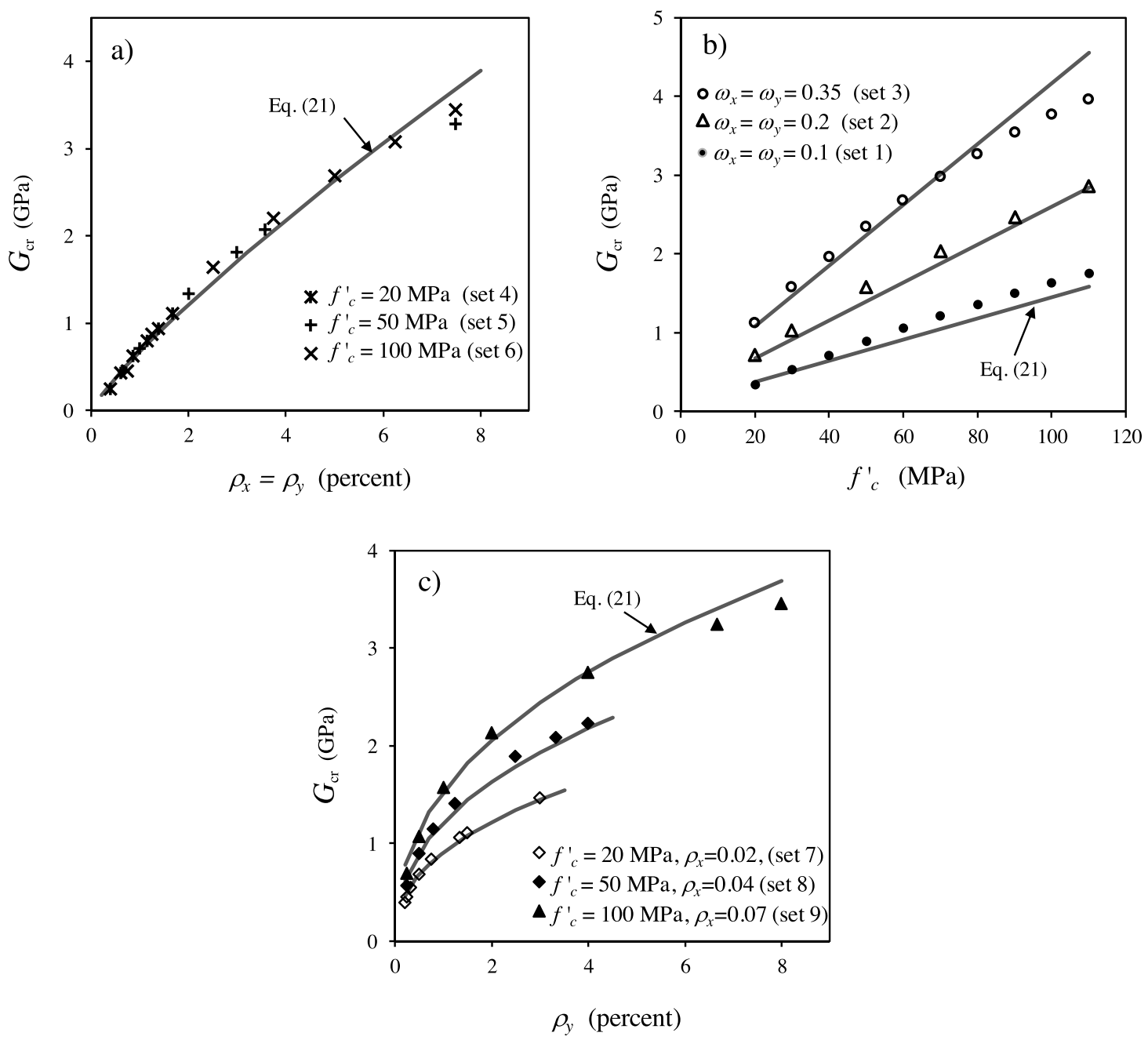

Figure 7. Development of equation for $G_{c r}$.

Figure 7(c) shows a plot of $G_{c r}$ versus $f_{c}^{\prime}$ for the results of sets 7 (NSC), 8 (MSC), and 9 (HSC). The x-reinforcement index and concrete strength were constant in each set. $G_{c r}$ increased as the amount of y- direction reinforcement increased. However, the rate of increase decreased as $\rho_{y}$ increased.

A best-fit of the results of nine sets of data can be obtained using the following equation:

$$
G_{c r}=32500\left(\rho_{x} \rho_{y}\right)^{0.42}
$$

where $G_{c r}$ is in MPa. The calculations of Eq. (21) are plotted in Figures 7 (a) to (c), and good agreement with the results of the MCFT is obtained.

The results indicate that the slope $G_{c r}$ was not significantly influenced by the compressive strength of the concrete. It depended mainly on the reinforcement ratios. This was clear from the results plotted in Figure 7(a), where elements with similar reinforcement had similar $G_{c r}$ in NSC, MSC, and HSC. 


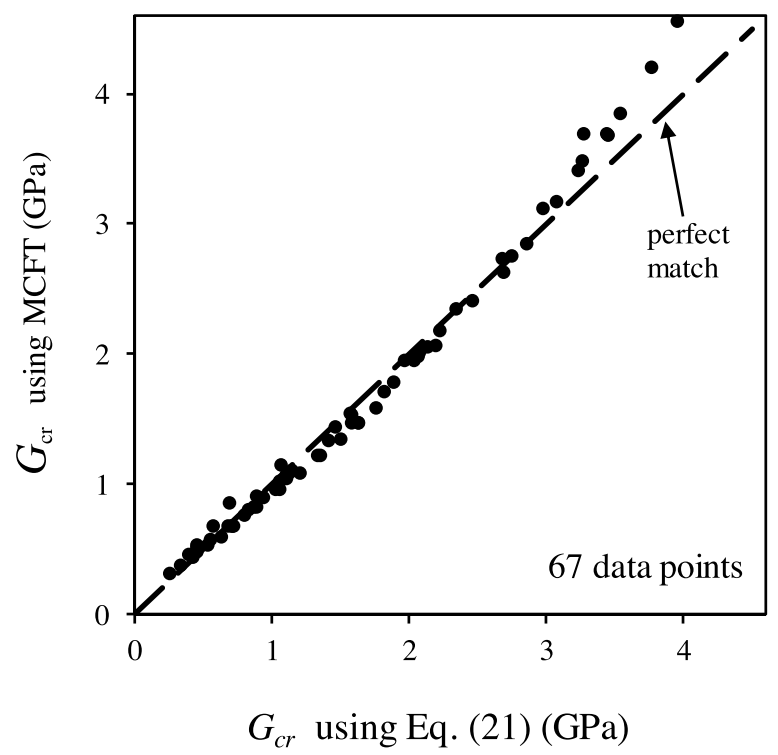

Figure 8. Comparison between $G_{c r}$ results from MCFT and Eq. (21).

Figure 8 compares $G_{c r}$ from the MCFT analyses with the calculations of Eq. (21). A very good agreement is obtained. The ratios of the values of $G_{c r}$ calculated using the MCFT to those calculated using Eq. (21) were obtained. The mean of the 67 ratios was 1.02 , and the coefficient of variation was $8 \%$. These results are listed in Table 2 .

\section{Shear strain and effective shear modulus at service}

When the values of $v_{0}$ and $G_{c r}$ are calculated using Eqs. (19) (or 20) and Eq. (21), the shear strain at service level stress can be obtained as $\left(v_{\text {ser }}-v_{0}\right) / G_{c r}$, or directly as

$$
\gamma_{s}=\frac{v_{\text {serv }}-0.3\left(f_{c}^{\prime}\right)^{0.4}}{32500\left(\rho_{x} \rho_{y}\right)^{0.42}}
$$

The corresponding effective shear modulus can be obtained as $G_{\text {ser }}=v_{\text {serv }} / \gamma_{s}$.

\section{Numerical example}

A numerical example illustrates why the calculations of the strains at service are affected by $G_{c r}$ more than $v_{0}$. It also shows the simplicity of the model. The following gives the calculation $G_{c r}, v_{0}, \gamma_{s}$ and $G_{s e r v}$ of HSC specimen VB3 tested by Hsu and Zhang (1998). The given properties of the element are $f_{c}^{\prime}=102.3 \mathrm{MPa} ; \rho_{x}=0.0598 ; \rho_{y}=0.0120$, $v_{u}=10.2 \mathrm{MPa}$. Hence, $v_{\text {serv }} \approx 0.7 v_{u}=0.7(10.2)=7.14 \mathrm{MPa}$.

The intercept stress $v_{0}$ is calculated using Eq. (19) as follows:

$v_{0}=0.3\left(f_{c}^{\prime}\right)^{0.4}=0.3(102.3)^{0.4}=1.91 \mathrm{MPa}$

The slope of the post-cracking linear response is calculated using Eq. (21) as follows:

$G_{c r}=32500\left(\rho_{x} \rho_{y}\right)^{0.42}=32500(0.0598 \times 0.012)^{0.42}=1554 \mathrm{MPa}$

The strain at service is calculated as $\gamma_{s}=\left(v_{\text {ser }}-v_{0}\right) / G_{c r}=(7.14-1.91) / 1554=3.37 \times 10^{-3}$. 
The effective shear modulus is calculated as $G_{\text {ser }}=v_{\text {ser }} / \gamma_{s}=7.14 / 0.00337=2120 \mathrm{MPa}$.

The experimentally observed strain at a stress of $7.14 \mathrm{MPa}$ is $2.92 \times 10^{-3}$. The ratio of the experimental to the calculated strain is 0.87 . If Eq. (20) was used instead of Eq. (19), $\gamma_{s}$ is calculated as $3.32 \times 10^{-3}$. The value of $v_{0}$ increases by $4 \%$, while the value of $\gamma_{s}$ is increased by $1.5 \%$ only. For this reason, it was stated earlier that the improvement provided in Eq. (20) has a less significant impact on the calculated shear strain at service conditions and is not warranted.

The strain calculated using the MCFT is $3.17 \times 10^{-3}$, and the corresponding ratio of the experimental to the calculated strain is 0.92 . If a linear-elastic behavior is assumed, with the modulus of elasticity of concrete $E_{c}$ equal to $4700 \sqrt{f_{c}^{\prime}}$ and Poisson's ratio equal to 0.2 , the service level strain is calculated as $0.36 \times 10^{-3}$. The ratio of the experimental to the calculated values of the strain is 8.1 .

\section{EXPERIMENTAL VERIFICATION}

In this section, the proposed equations are evaluated based on their ability to model the post-cracking response of $\mathrm{RC}$ membrane elements, and the calculation of the shear strains at estimated service stress levels.

Data was collected from $17 \mathrm{RC}$ elements tested under strain control conditions at the University of Houston (Pang and Hsu, 1995; Hsu and Zhang, 1998). The MCFT was developed based on a different set of experimental data from tests conducted at the University of Toronto under stress control conditions. The 17 Houston tests were used by Bentz (2000) to provide an unbiased evaluation of the MCFT. They are used here to provide a similar unbiased evaluation of the proposed equations.

\section{Post-cracking response}

The part of the response modeled by the proposed equation extends from the end of the transition zone (following concrete cracking stress) to the peak stress. The peak stress is calculated using a simple model developed by the author (Rahal 2008).

Figures 9 and 10 plot the post-cracking lines based on Eqs. (19) and (21) and compare them with the experimental results from ten membrane elements (Pang and Hsu, 1995; Hsu and Zhang, 1998). The response curves calculated using the MCFT are also plotted. The six elements shown in Figure 9 were under-reinforced. Three of the elements shown in Figure 10 were partially under-reinforced and one was over-reinforced. Half of the elements shown in Figures 9 and 10 are normal strength concrete ( $f_{c}^{\prime}$ from 41 to $44 \mathrm{MPa}$ ) and the remaining ones are high strength concrete $\left(f_{c}^{\prime}>95 \mathrm{MPa}\right)$. Table 3 summarizes the properties of the thin RC specimens. The figures show that the simplified equations (19) and (21) compared well with the experimental results and provided a fairly accurate representation of the calculations of the MCFT.

Table 3 also reports the values of $v_{0}$ and $G_{c r}$ obtained from the experimental results and compares them with the calculations of Eqs. (19) and (21). The ratios of the experimentally observed to the calculated values are also listed. The average of the 17 ratios for $v_{0}$ was 0.99 , and the coefficient of variation was $21.5 \%$. For $G_{c r}$, the average of the ratios was 1.03 , and the coefficient of variation was $18.7 \%$. The results are considered adequate, especially that Eqs. (19) and (21) were not fine-tuned based on experimental results. 

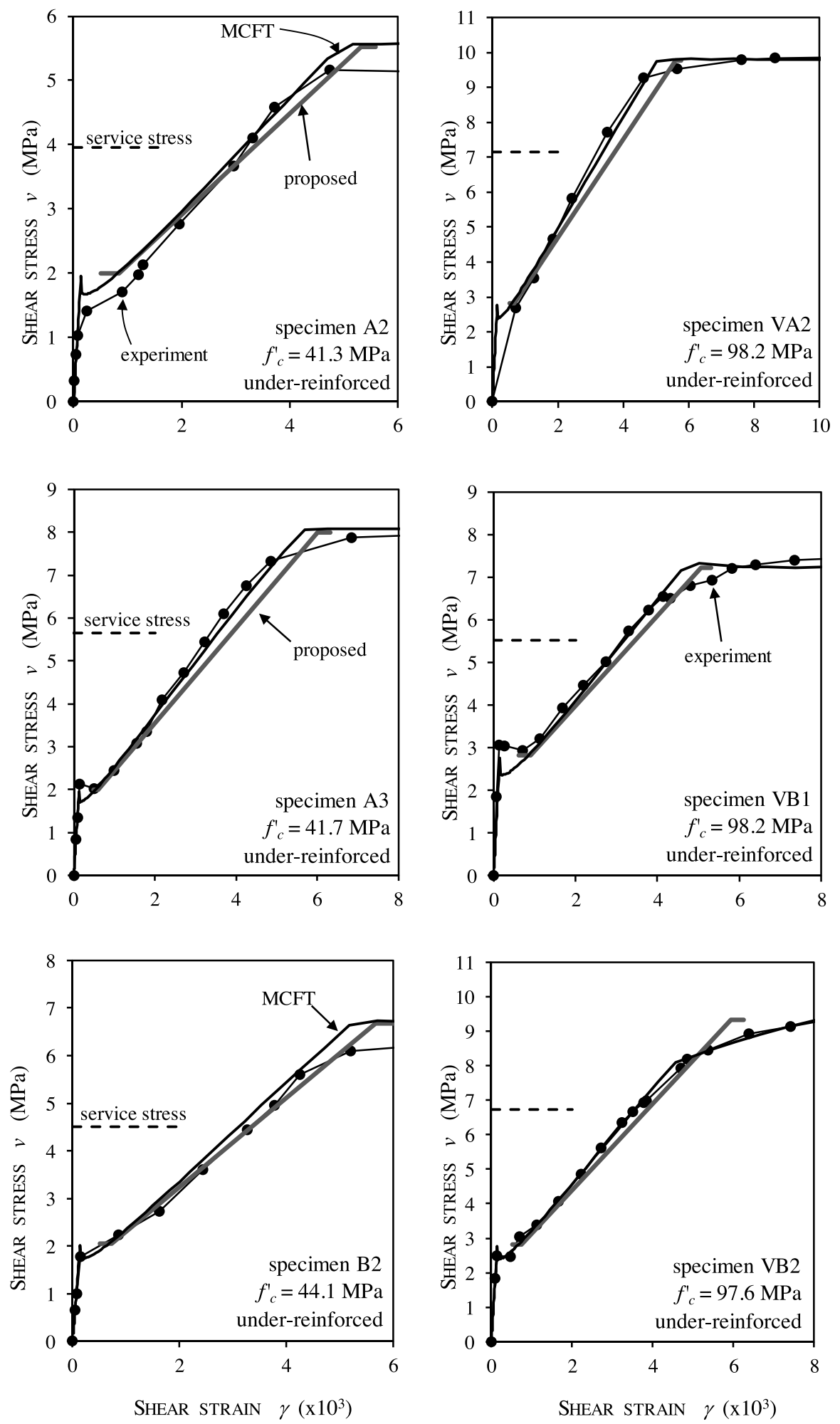

Figure 9. Comparison between observed and calculated post-cracking response for under-reinforced membranes (Pang and Hsu, 1995; and Hsu and Zhang, 1998). 

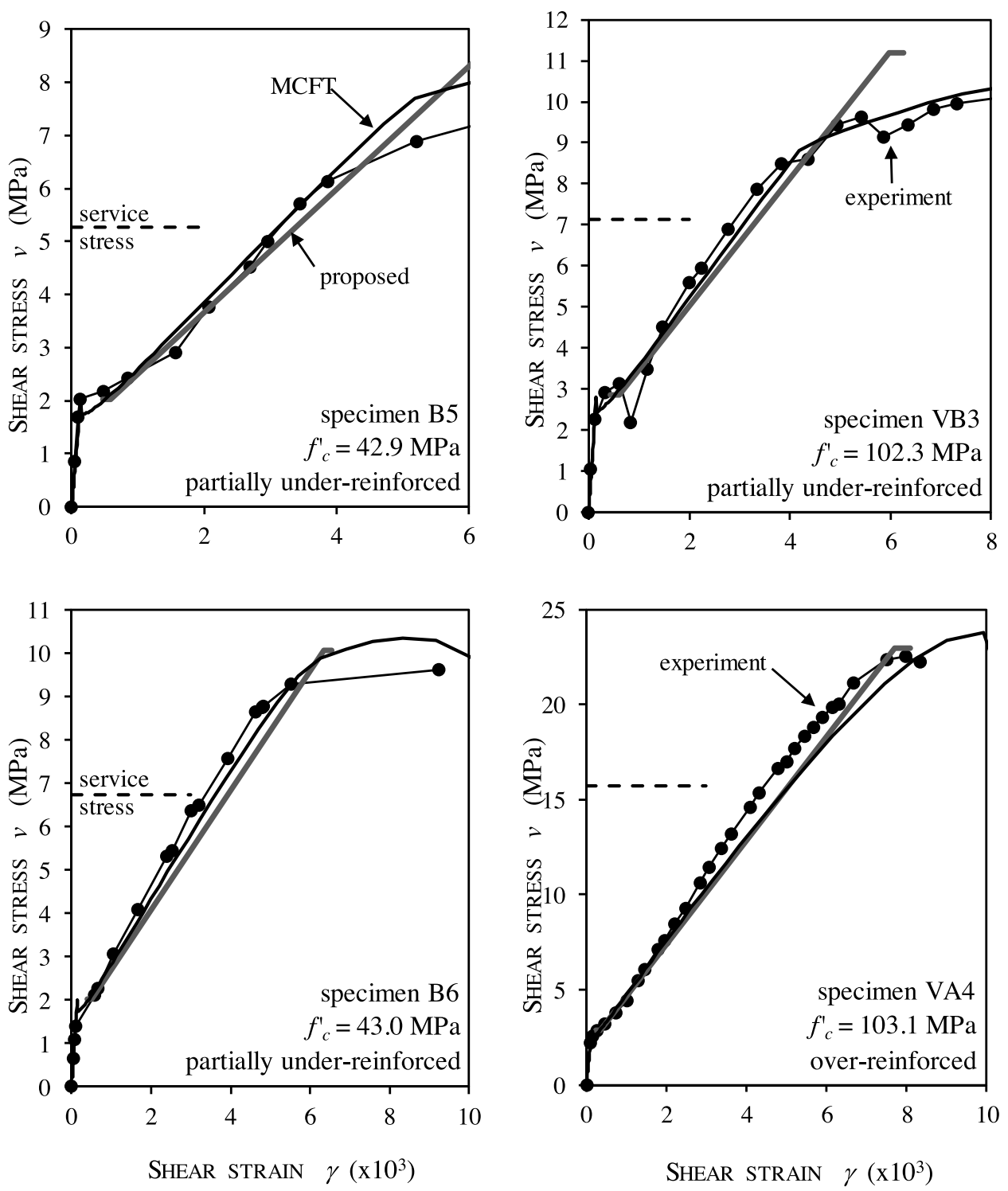

Figure 10. Comparison between observed and calculated post-cracking response for partially under-reinforced and over-reinforced elements (Pang and Hsu, 1995; and Hsu and Zhang, 1998)

\section{Shear strains at service}

As shown in the numerical example, the shear strains at estimated service loads can be easily obtained when $v_{0}$ and $G_{c r}$ are calculated. Table 3 lists the service level stresses $v_{s e r v}$ which were estimated to be equal to $70 \%$ of the experimentally observed ultimate shear strengths. 


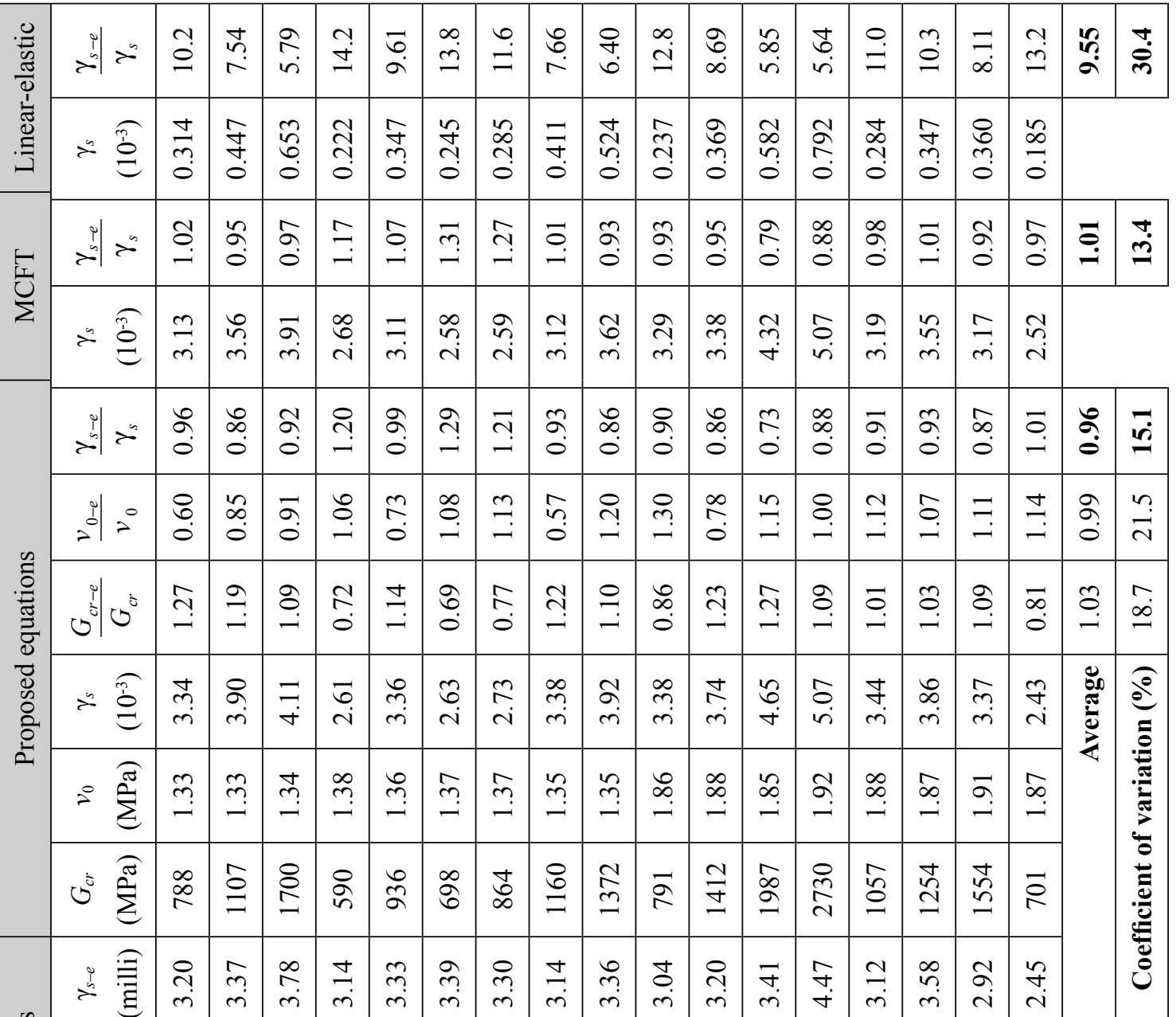

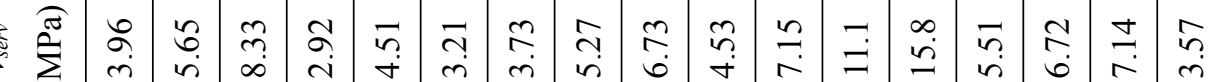

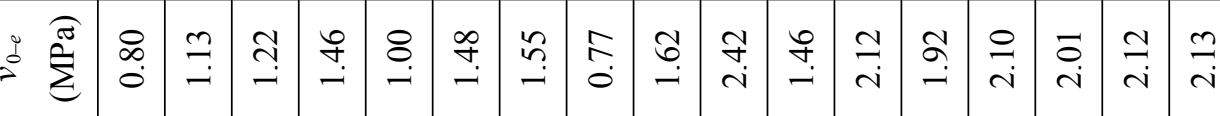

0

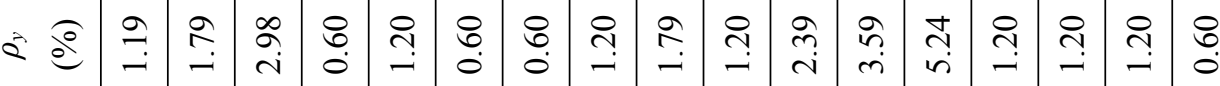

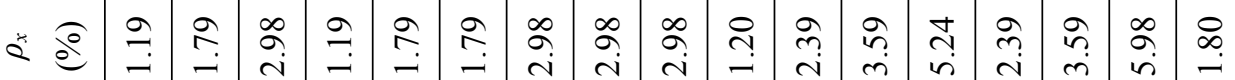

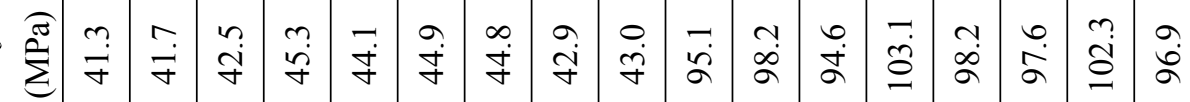

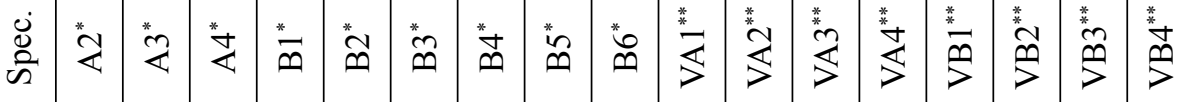


Table 3 also lists the strains $\gamma_{s-e}$ corresponding to $v_{\text {serv }}$ from the experimentally obtained response curves, and the strains $\gamma_{s}$ calculated using the proposed equations. It also lists the strains obtained using the MCFT analyses in addition to those obtained using the an uncracked linear-elastic analysis. Figure 11 plots the results of the comparison. The ratios of the experimental to the calculated strains are computed for each method, and the results are listed in Table 3. For the proposed equations, the average of the 17 ratios was 0.96 , and the coefficient of variation was $15.1 \%$. These values were 1.01 and $13.4 \%$ for the results of the MCFT, respectively. It is observed that the accuracy of the proposed simple equations is comparable to that of the iterative MCFT. This is also evident from Figure 11. The average and coefficient of variation corresponding to the ratios based on linear-elastic uncracked behavior were 9.55 and $30.4 \%$, respectively. As expected, the strains calculated using the traditional approach were nearly an order of magnitude smaller than the experimental results.

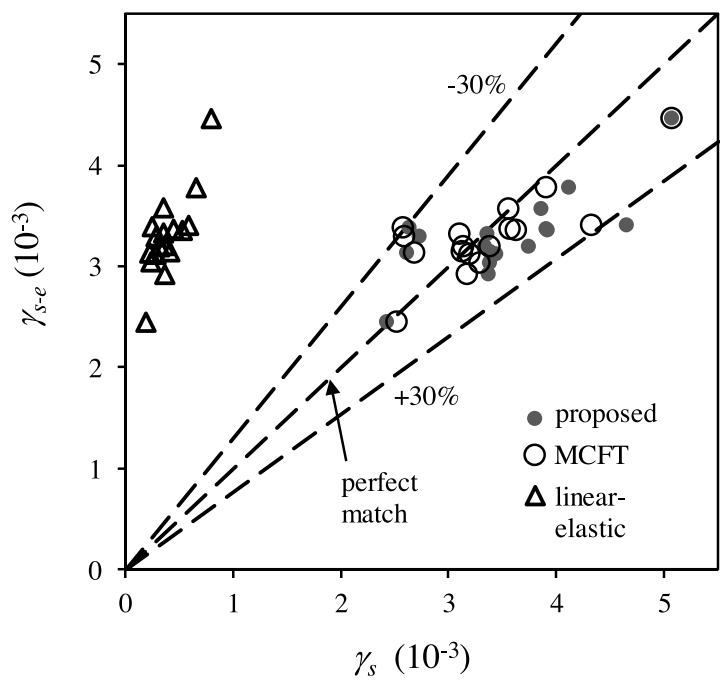

Figure 11. Comparison between observed and calculated shear strains at service stress.

\section{SUMMARY AND CONCLUSIONS}

This paper presented two simple equations that can be used to calculate the post-cracking pre-peak part of the shear stress-strain response curve of RC membrane elements. Membranes subjected to service level of stresses are within this part of the response, and hence the model can be used to calculate the shear strains at service conditions.

The post-cracking response was modeled as a straight line. The slope of the line represents the post-cracking shear modulus $G_{c r}$ and the constant represents the intercept stress $v_{0}$ at zero strain. The results of the MCFT were used to identify the main factors that influence the two constants needed to model the linear response. The shear modulus was found to depend mainly on the ratios of the orthogonal reinforcement, while the intercept stress was found to depend mainly on the tensile strength of the concrete. Two simple equations were proposed.

The post-cracking response calculated using the proposed equations was compared with the experimentally observed post-cracking stress-strain response from RC membrane elements and with the calculations of the MCFT for these elements. A very good agreement was observed.

The model was also used to calculate the shear strains corresponding to shear stresses at service conditions. The ratio of the experimentally observed to the calculated shear strains was computed for the 17 specimens. The average of the ratios was 0.96 , and the coefficient of variation was $15.1 \%$. For the calculations of the MCFT, the average of the ratios was 1.01 , and the coefficient of variation was $13.4 \%$. The accuracy of the proposed equation was, hence, comparable to that of the iterative MCFT. The calculations based on an uncracked linear-elastic behavior severely underestimated the service shear strains. The average of the ratios of the observed to the calculated strains was 9.55, and the coefficient of variation was $30.4 \%$. 


\section{ACKNOWLEDGMENT}

The research reported in this paper was supported by Research Sector, Kuwait University, Research Grant EV03/12. This support is gratefully acknowledged.

\section{NOTATIONS}

$a_{g} \quad=\quad$ nominal maximum aggregate size

$E_{c} ; E_{s}=\quad$ moduli of elasticity of concrete and steel, respectively

$f_{c}^{\prime}=$ compressive strength of concrete

$f_{c r} \quad=\quad$ tensile strength of concrete

$f_{1}=$ principal tensile stress in concrete

$f_{2}=$ principal compressive stress in concrete

$f_{2-\max }=\quad$ softened compressive strength in concrete

$f_{s}=\quad$ stress in steel

$f_{s x} ; f_{s y}=\quad$ average stress in steel in $\mathrm{x}$ - and $\mathrm{y}$-directions respectively

$f_{s x-c r}=\quad$ stress in steel in $\mathrm{x}$-direction at crack location

$f_{s y-c r}=\quad$ stress in steel in y-direction at crack location

$f_{y}=$ yield strength of reinforcement

$f_{y-x}=\quad$ yield strength of $\mathrm{x}$-reinforcement

$f_{y-y}=\quad$ yield strength of y-reinforcement

$G_{c r}=$ post-cracking shear modulus

$G_{c r-e}=$ post-cracking shear modulus based on experimental data

$G_{\text {serv }}=\quad$ effective cracked shear modulus at service conditions

$G_{\text {uncr }}=\quad$ shear modulus before cracking

$K_{T S}=$ factor in tension-stiffening equation

$S_{x}=\quad$ vertical distance between x-direction bars

$S_{y}=$ horizontal distance between y-direction bars

$S_{\theta} \quad=\quad$ average spacing of diagonal cracks

$v=$ shear stress

$v_{0}=$ calculated intercept stress at zero strain

$v_{0-e}=\quad$ intercept stress based on experimental data

$v_{c i}=$ limiting shear stress on the crack surface

$v_{c r}=\quad$ cracking shear stress

$v_{\text {sev }}=\quad$ estimated service shear stress

$v_{u}=$ nominal ultimate shear strength 


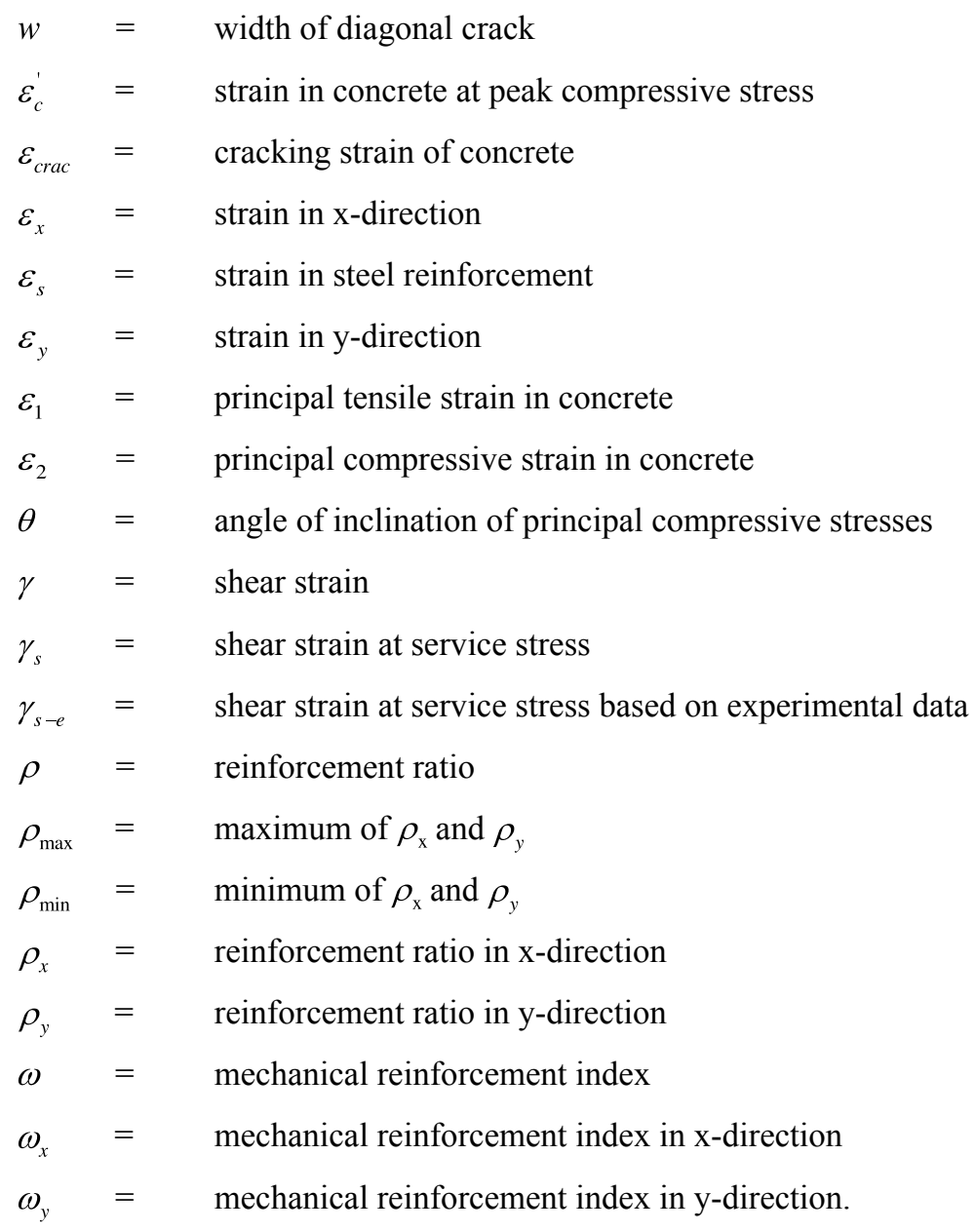

\section{REFERENCES}

Al-Shaleh, K.S. \& Rahal, K.N. (2007). Shear behavior of K850 reinforced concrete beams with low transverse reinforcement," Kuwait Journal of Science and Engineering, 34(2): 35-54.

Bentz, E.C. (2000). Sectional analysis of reinforced concrete members. Toronto, University of Toronto.

Beyer, K., Dazio, A. \& Priestley, N. (2011). Shear deformations of slender reinforced concrete walls under seismic loading. ACI Structural Journal, 108: 167-177. https://doi.org/10.14359/51664252.

Bræstrup, M.W. (1974). Plastic analysis of shear in reinforced concrete. Magazine of Concrete Research, 26(89): 221-228. https:// doi.org/10.1680/macr.1974.26.89.221.

Collins, M.P., Mitchell, D., Adebar, P. \& Vecchio, F. J. (1996). A general shear design method. ACI Structural Journal, 93(1): 36-45. https://doi.org/10.14359/9838.

Collins, M.P., Mitchell, D. \& Macgregor, J.G. (1993). Structural design considerations for high-strength concrete. Concrete international, 15(5): 27-34.

Debernardi, P.G. \& Taliano, M. (2006). Shear deformation in reinforced concrete beams with thin web. Magazine of Concrete Research, 58(3): 157-172. https://doi.org/10.1680/macr.2006.58.3.157.

Hansapinyo, C., Chaisomphob, T. \& Makawa, K. (2003). Shear deflection of reinforced concrete beams with shear reinforcement after diagonal cracking. The Ninth East Asia-Pacific Conference on Structural Engineering and Construction, RCS20-25.

Huang, Z., Tu, Y., Meng, S., Sabau, C., Popescu, C. \& Sas, G. (2019a). Experimental study on shear deformation of 
reinforced concrete beams using digital image correlation. Engineering Structures, 181: 670-698. https://doi.org/10.1016/j. engstruct.2018.12.056.

Huang, Z., Tu, Y., Meng, S., Bagge, N., Nilimaa, J. \& Blanksvärd, T. (2019b). Validation of a numerical method for predicting shear deformation of reinforced concrete beams. Engineering Structures, 197, 109367. https://doi.org/10.1016/j. engstruct.2019.109367.

Khalifa, J. (1986). Limit analysis of reinforced concrete shell elements, PhD thesis, Department of Civil Engineering, University of Toronto, Toronto, Ontario, Canada.

Nilson, A.H., Darwin, D. \& Dolan, C.W. (2010). Design of concrete structures, New York, USA: McGraw-Hill.

Pang, X.B.D. \& Hsu, T.T. (1996). Fixed angle softened truss model for reinforced concrete. Structural Journal, 93(2): 196-208. https://doi.org/10.14359/1452.

Pang, X.B.D. \& Hsu, T.T. (1995). Behavior of reinforced concrete membrane elements in shear. Structural Journal, 92(6): 665679. https://doi.org/10.14359/9661.

Rahal, K.N. (2010). Post-cracking shear modulus of reinforced concrete membrane elements. Engineering Structures, 32(1): 218225. https://doi.org/10.1016/j.engstruct.2009.09.008.

Rahal, K.N. (2008). Simplified design and capacity calculations of shear strength in reinforced concrete membrane elements. Engineering Structures, 30(10): 2782-2791. https://doi.org/10.1016/j.engstruct.2008.03.002.

Vecchio, F.J., Collins, M.P. \& Aspiotis, J. (1994). High-strength concrete elements subjected to shear. ACI Structural JournalAmerican Concrete Institute, 91(4): 423-433. https://doi.org/10.14359/4149.

Vecchio, F.J. \& Emara, M.B. (1992). Shear deformations in reinforced concrete frames. ACI Structural journal, 89(1): 46-56. https://doi.org/10.14359/1283.

Vecchio, F.J. \& Collins, M.P. (1986). The modified compression-field theory for reinforced concrete elements subjected to shear. ACI J., 83(2): 219-231. https://doi.org/10.14359/10416.

Vecchio, F.J. \& Collins, M.P. (1982). The response of reinforced concrete to in-plane shear and normal stresses. Publication No (82-03), University of Toronto.

Zhang, L.X.B. \& Hsu, T.T. (1998). Behavior and analysis of $100 \mathrm{MPa}$ concrete membrane elements. Journal of Structural Engineering, 124(1): 24-34. https://doi.org/10.1061/(asce)0733-9445(1998)124:1(24). 